\title{
MATERIAL OPTIMIZATION DURING MEDICAL COMPONENTS DEVELOPMENT IN SELECTIVE LASER SINTERING PROCESS USING VALUE ENGINEERING
}

\author{
Sunil Kumar Tiwari ${ }^{1}$, Sarang Pande ${ }^{2}$, Santosh M. Bobade ${ }^{3}$ \\ ${ }^{1}$ PhD Scholar, Department of Mechanical Engineering, Jaypee University of Engineering \& Technology, Guna, M.P.- \\ 473226, India \& Associate Professor, Department of Mechanical Engineering, Lakshmi Narain College of \\ Technology and Science, Bhopal, M.P. - 462021, India \\ ${ }^{2}$ Professor, Department of Mechanical Engineering, Marwadi Education Foundations Group of Institutions, Rajkot- \\ 360003, India \\ ${ }^{3}$ Assistant Professor, Department of Physics, Jaypee University of Engineering \& Technology, Guna, M.P.-473226, \\ India
}

\begin{abstract}
Additive Manufacturing (AM) technique provides a hi-tech tool for making solid free form products. Selective Laser Sintering $(S L S)$ is one of the AM technique which uses wide range of materials for making end use products. SLS process has potential to produce superior quality product at low cost and in shorter lead times which gives more customer delights. At present limited materials are accessible with very high cost that impedes increasing number of applications of SLS. To make this technology feasible suitable selection of material and fabrication of product which suit the requirement of application economically is very important. Value Engineering (VE) technique is used to optimize the material during medical components/ devices development using SLS process and it would benefits in producing high strength parts with good aesthetic quality which satisfying the customer needs. VE aims to identify unnecessary cost associated with any product, material, parts, component, system or service by analysis of functions and efficiently eliminating them without impairing the quality and functional reliability and provides optimality.
\end{abstract}

Keywords: Biomedical, Medical Devices, Selective Laser Sintering, Material Properties, Value Engineering, $* * *$

\section{INTRODUCTION}

Additive manufacturing (AM) is a latest automated manufacturing process which allows manufacture of physical models of any complexity by means of layer-bylayer deposition technique directly from computer aided design (CAD) model by selective fusion, sintering or polymerization of material as reported by Jain et al. [1-3]. AM processes are also energy saving, high productive and sustainable manufacturing process [4-5]. AM process reduces the time and cost to the highest degree which is necessary to bring a new product in the market with preference to create any kind of geometry without using any special tool, as necessary in the case of conventional manufacturing [6-7]. The AM technique initiative was introduced in late 1980s. AM techniques have been made commercially accessible in the market during last 26 years. The first AM technique, SLA by 3D systems in year 1988 has grown to be the initiate in the AM market. Initially, AM system was bigger in size, more costly and the parts made from them were limited to specific applications only (i.e. for making prototypes) [8]. At present, there are more than 50 vendors around the world selling a large range of $\mathrm{AM}$ systems, with each system having its own strengths, limitations and applications [9]. Other than SLA at present several AM technologies exists, classified as, Selective Laser Sintering (SLS), Selective Laser Melting (SLM), Fused Deposition Modeling (FDM), Laminated Object Manufacturing (LOM), 3DPrinting (3DP) etc. where Tiwari et al. (2015) reported four latest technologies namely, Electron Beam Melting (EBM), ProMetal, Laminated Engineered Net Shaping (LENS) and Polyjet which is added in year after 2004[1]. AM systems vary mainly based on materials they use to make the part, for e.g. powder, filament, and liquid raw state. Secondly, based on the process to make model e.g. SLS, SLA, FDM, LOM, LENS, etc.

AM systems classified on the kind of raw materials used for manufacturing is as, Liquid based: Stereolithography (SLA), Polyjet technology, Solid Curing System (SCS), Digital 
Light Processing (DLP), E-Darts, Solid Object Ultraviolet, 3D Bioplotter and Acculas technology, Solid based: Fused deposition modelling (FDM), Shape Deposition Manufacturing, Benchtop System, Laminated Object Manufacturing (LOM), and CAM-LEM technology and Powder based: Selective Laser Sintering (SLS), 3D Printing (3DP), Electron Beam Melting (EBM), Laser Engineering Net Shaping (LENS), Selective Mask Sintering (SMS) and Voxjet system [1], [9-10].

These AM techniques have capabilities to create any kind of geometry simply, cost effectively and efficiently as compared to conventional manufacturing [3]. This makes AM technique viable and suitable in various field of manufacturing. Wholers [11] reported in their annual worldwide growth report of additive manufacturing and 3D printing state of the industry that the total annual revenue for the AM industry for year 2010-11 has been well over $\$ 1$ billon and it is predicted to grow about $\$ 3.7$ billion by year 2019. The system sale for AM was approximate 2800 unit machines in year 2005 and above 6000 unit machines in year 2010. Fig. 1 shows the AM system sales worldwide. The registered growth for AM process was about $24 \%$ in year 2010 and about $26 \%$ compound growth rate until year 2010. Likely $26.3 \%$ of all industrial AM systems installed worldwide are in the Asia/Pacific region. Meanwhile, 29.1\% are in Europe and $40.2 \%$ are in North America region. The remaining $4.4 \%$ are in Central America, South America, the Middle East, and Africa. Fig. 2 shows the cumulative distribution of industrial AM systems in the Asia/Pacific region through the end of year 2011.

The Fig-2 shows that the greater part of the systems is in Japan and China. The "Other" subdivision includes Brunei, Indonesia, Mongolia, New Zealand, the Philippines, Singapore, and Vietnam in Asia's adoption of AM for modelling and prototyping applications. The data available shows that is Asia's region fewer organizations are using AM to the production of parts for final products.

Fig-3 show the use of AM for the direct production of parts and it is find that end up in final products continues to grow. In last nine years, it has gone from virtually nothing to $24 \%$ of the total product and service revenues from additive manufacturing. Fig-4 shows the percentage of response for different AM processes [12]. Amongst all available AM processes as well as others like vacuum casting process, the percentages uses value of SLS process in all is very high and it is having about $25 \%$ as compression to the others process [12].

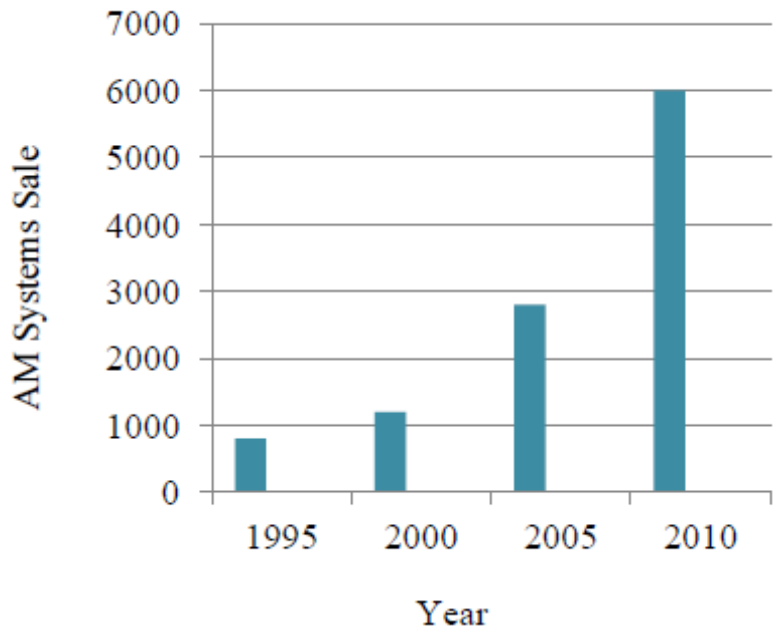

Fig-1: AM growth trend

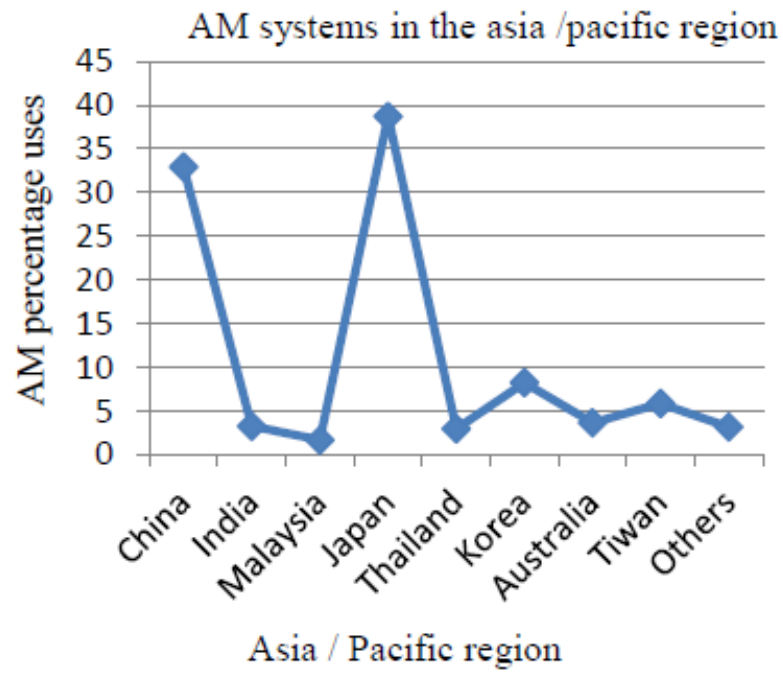

Fig-2: AM systems in the Asia/Pacific region by the end of year 2011

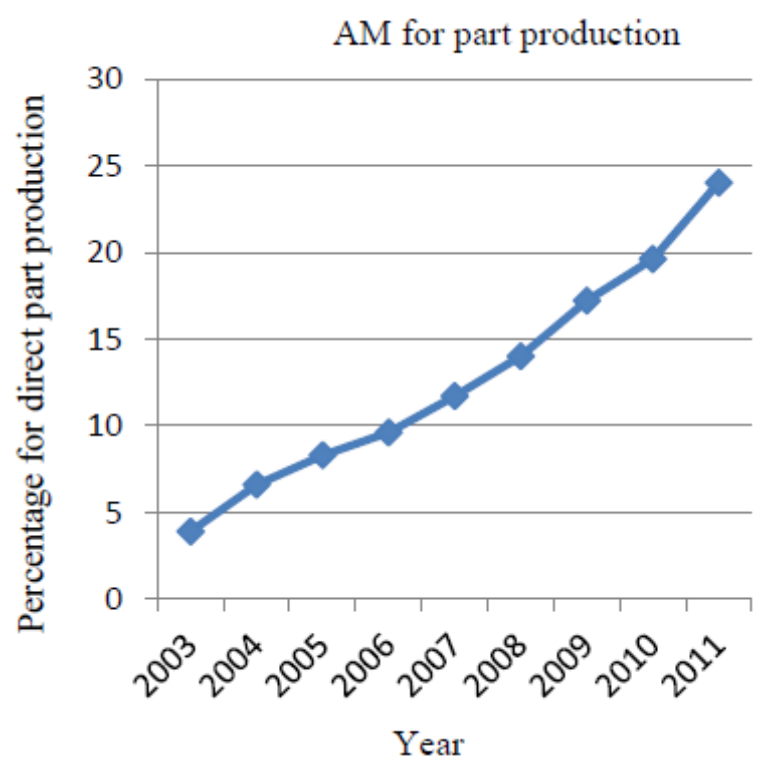

Fig-3: Use of AM for direct part production worldwide 


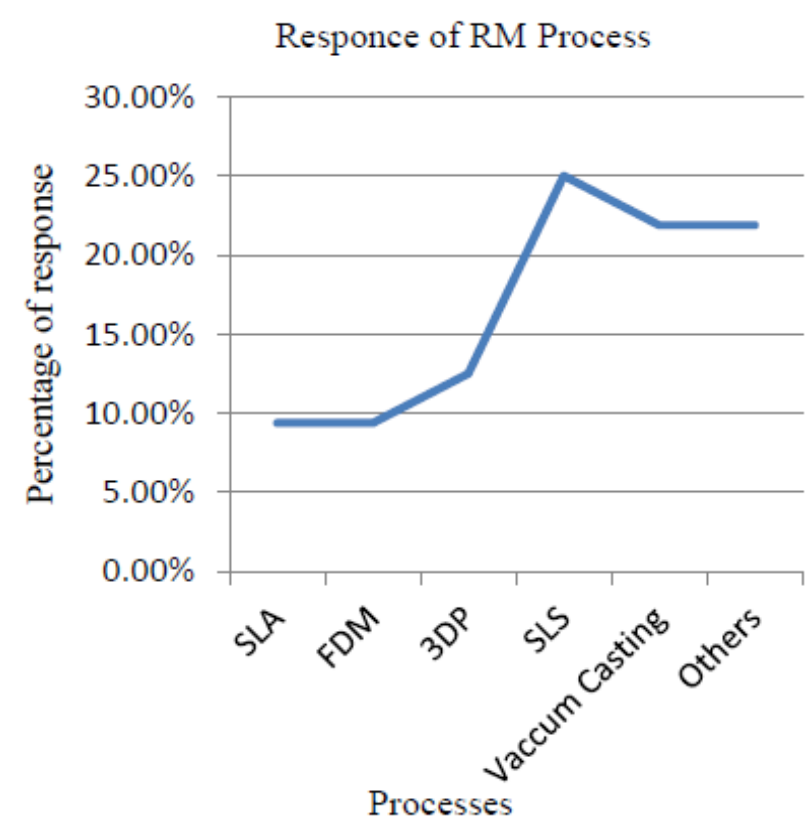

Fig-4: Percentage of response for different AM processes [12]

\section{SELECTIVE LASER SINTERING}

SLS is a $3 \mathrm{D}$ printing process having average to fast speed and average to good accuracy and surface finish [10], [1315]. SLS machine consists of controller unit, powder feed cylinder, process chamber, part bed chamber, layering roller mechanism, $\mathrm{CO} 2$ laser beam and optical scanner system and environmental control unit as shown in Fig-5 [10]. The process starts with preheating the process chamber of SLS machine just below the melting point of the powder material. The layering roller mechanism deposits powder on part bed chamber of particular layer thickness equal to the diameter of the power material. Optical laser scanner scans the part slice geometry with the help of galvanometers. The $\mathrm{CO} 2$ laser beam (ranging from $50 \mathrm{~W}$ to $18 \mathrm{KW}$ ) fuses the powder at specific location for each layer as per specified design. The part build cylinder piston is lowered by equal amount as that of powder feed cylinder is elevated and is equivalent to the amount of the layer thickness for each time to create physical part. The positioning of piston is controlled through the servomotors mechanism. SLS working process begins with creating CAD model of the part with CAD software or using any special software which allows users to create CAD or STL data from CT or MRI scan transferred to the SLS machine or by converting CAD model into additive processes standard STL file format which represents the skin of the 3-D model as a set of triangles, slicing the CAD or STL file into thin layers. User prepares the 3D model for build up by designating the location and orientation of the part in the machine. During build up, slices of the model in form of thin layers along the $\mathrm{X}-\mathrm{Y}$ plane are laid successively over each layer, moving upward in the $\mathrm{Z}$ direction and building part one layer at a time the physical part is fabricated. Post processing of the part is final steps in which small cleaning and surface finishing, such as sanding, coating, or painting can be performed in order to improve the part's surface quality[12], [10].

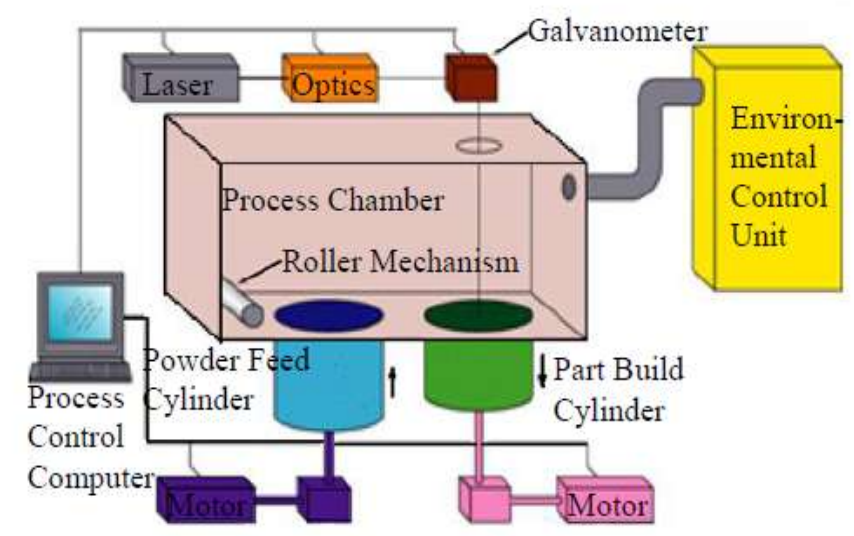

Fig-5: SLS process machine

\subsection{Selective Laser Sintering Applications}

Area of applications of SLS depends on the purpose of part to be formed and availability of varying characteristics materials. SLS process uses wide range of materials to make prototypes; functional prototypes and end use products for various fields of applications like biomedical, engineering (aerospace, automobile, architectural etc.) and some others gives it an edge over other AM techniques. Due to compressed time from conceptualization to producing parts for selling, SLS process accepted for wide range of applications. In design field, it is used for CAD model design specification examination, visualizing parts, proving idea, marketing and presentation model, in engineering analysis and planning used for form and fit models, flow analysis, stress distribution analysis, pre series parts, diagnostic and pre-surgical operation planning, design and fabrication of custom prostheses and implants, scaffold fabrication for tissue engineering, orthodontics and hearing aids, manufacturing of medical devices and in field of manufacturing and tooling as a tooling mold parts, casting. EDM electrodes and master models in the field of motor vehicles which includes application areas as aerospace, business machines, medical, architectural, jewellery, government/ military work and apart from these it has been 
also accepted and becomes powerful tool for art and hobbyist people. Fig-6 shows the different uses of AM processes in which it is mostly used for making functional prototype of 1600 numbers applications [16]. Fig-7 describes the different Uses for AM Process year 2011[12]. In the total acceptability of AM worldwide motor vehicle covers $31.7 \%$ and consumer products about $18.4 \%$ (majorly) where as left over are others as shown in Fig-7 [12]. Fig-8 describes the different uses for SLS Process by year 2012. In the total acceptability of AM worldwide both motor vehicles covers $19.5 \%$ and consumer products about $20.3 \%$ covers majorly where as remaining are others as shown in Fig$8[11]$.

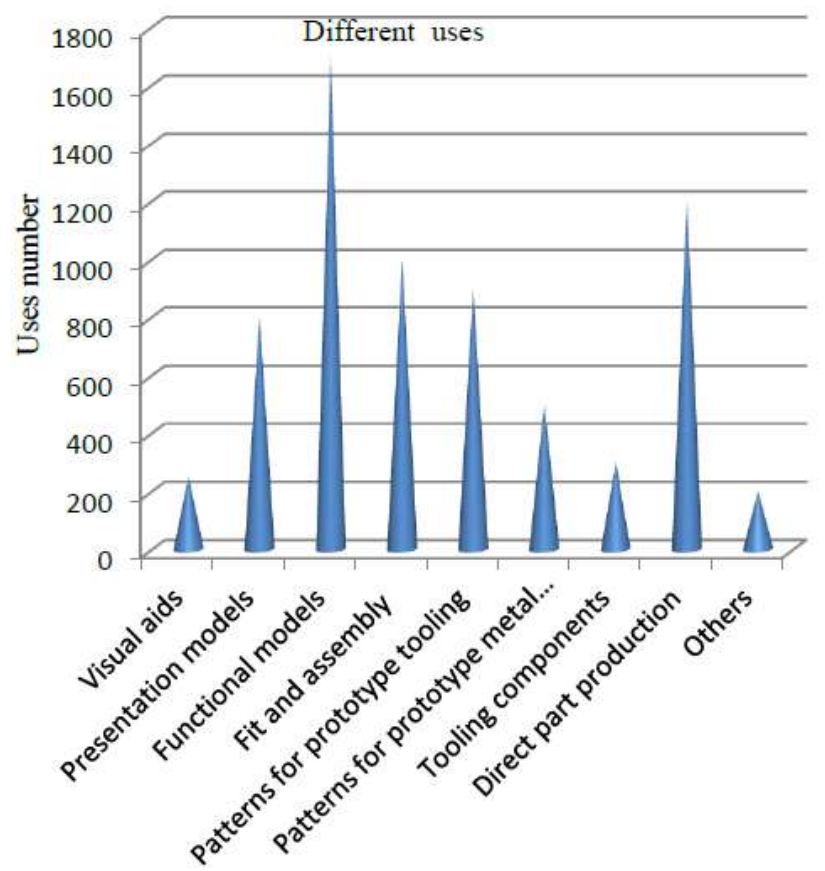

Fig-6: Different uses of AM processes [16]

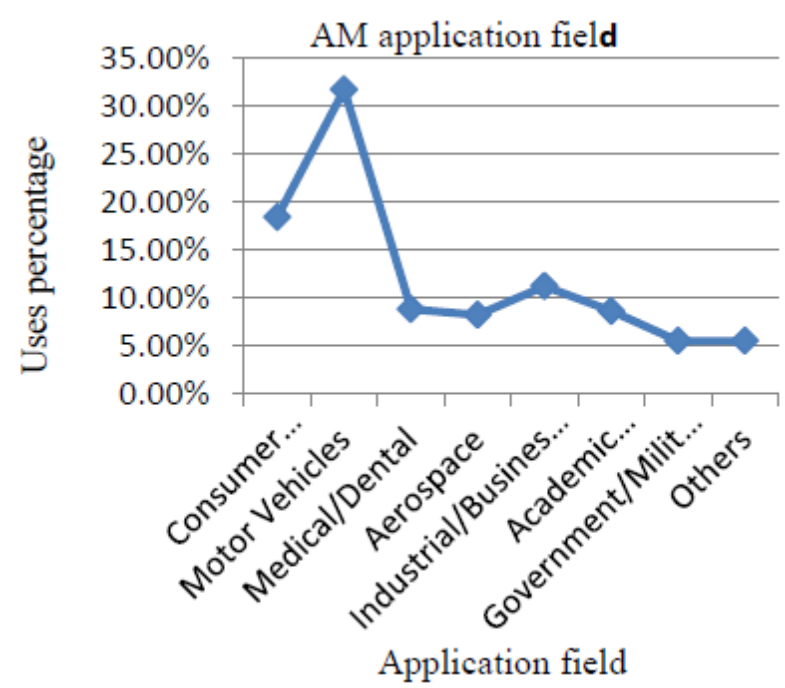

Fig-7: AM uses market status by year 2011[12]

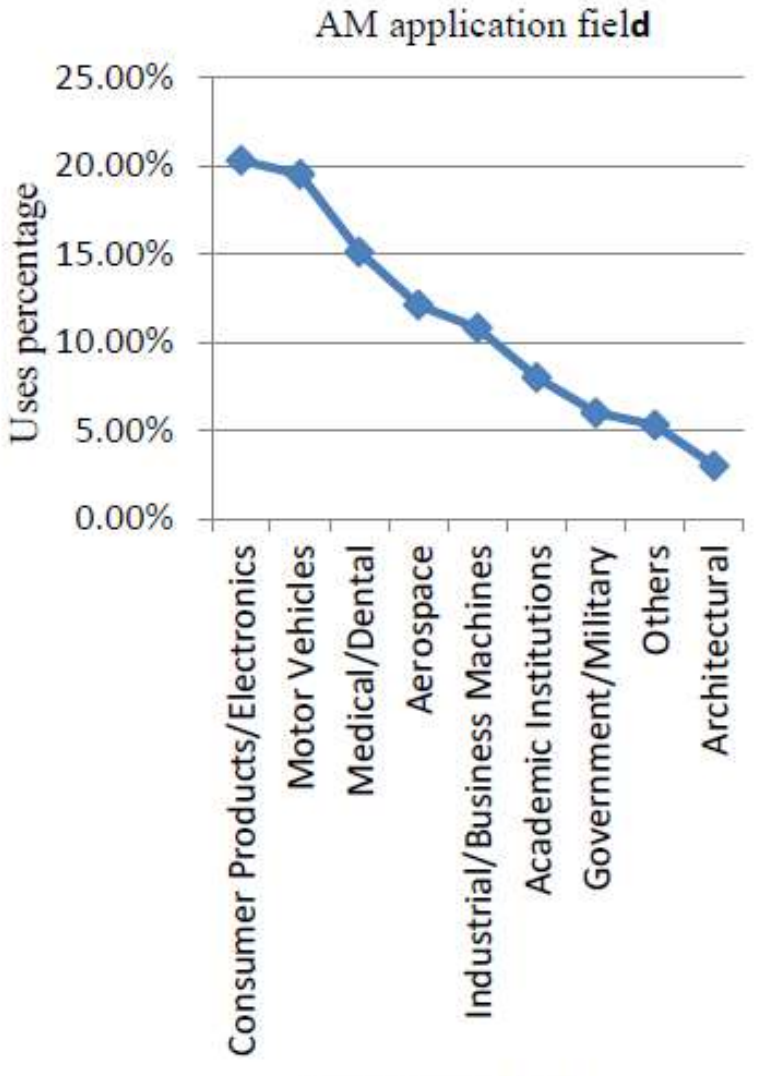

Application field

Fig-8: AM uses market status by year 2012 [11]

\section{VALUE ENGINEERING}

SLS technology has made significant strides over the past 26 years, but challenges are still having with this process. These are primarily associated to materials and process [10]. To manage these challenges Value Engineering (VE) approach is used. VE is a proven, effective and sustainable tool for continuous improvement and design enhancement. Value Engineering aims to identify unnecessary cost associated with any product, material, parts, component, system or service by analysis of functions and efficiently eliminating them without impairing the quality and functional reliability and provides optimality [17]. VE uses lowest life cycle cost, to realize the necessary function consistently, and cultivate the potential to reduce the cost, and discover the ways to enhance the value of the product [18-19]. We are users and in user's stand point of view , using value engineering analysis principle and method to guide, organize and appraise innovation, to study how to enhance the quality of products and how to reduce the reduce the cost, then to design new product or the oddness product with high quality which could meet the customer's requirements. Thus, enterprise or company could make more profit, the enterprise's technological innovation could have the explicit direction which will lead enterprise competence. The relation between cost, value and function is expressed as: 


$$
\text { Value }(\mathrm{V})=\text { Function } / \text { Cost }=\mathrm{F} / \mathrm{C}
$$

Equation (1)

Where, Function $=$ the exact work that a design or a product or part must perform.

The VE formula indicates that, Value depends on the function and the cost, depends on the combination of the function and the cost. There are two ways to enhance products value, one is to decrease production cost and other is to remove product's unnecessary functions. Following critically examination of the above VE formula, we identify that there are several ways to improve product's value i.e. F maintains, cost reduces; cost maintains, function increases; function decreases a little, cost decreases more in fact; Cost increases a small, while function increases more in fact. When the customer evaluates the mechanical product which he wants to buy, he always considers the usefulness of this product and if it worth to buy. Only combine the product function with its cost, combine the technical indicator with economic indicator, can we produce high-quality and lowprice products, and make more profit. In recent years, some studies have been limited to apply VE in management information system. architectural field, customer value analysis, government bid procurement etc [18]. Particularly, very little attention has been given to studying in optimization of material for selective laser sintering process of AM. The purpose of value engineering is to validate, the design and material of the assembly or subassembly or Part of the product and to step back and look at the total image and function for SLS process. Therefore, the specific objective of this paper to undertake a study to adopt the VE method in SLS process and reduced the cost of material without impairing the function of the product.

In this regards they approaches to get the answer of questions related what is the item? What function does it perform? What does it cost? What else will do the function? What will be the cast? Value engineering procedure steps consist of orientation phase, information phase, functional analysis phase, development phase, presentation phase, implementation phase and follow up phase.

Phases of VE: Various VE phases are described on below.

- Orientation phase: It involves identification of problem very clearly, selection of project, lying down objective and target and in depth training of all the members.

- Information phase: This phase start after clearly identifying what is to be accomplished. In this phase all the relevant information, like material, drawing and technical specification, manufacturing processes, detail cost break, performance/failure report, quality, procurement and production problem is gathered in short.

- Functional analysis phase involves analysis and identification of functions.

- Creative phase: This phase is the essence of value engineering. In this phase all the possible alternative are generated. This can be achieved by brainstorming and other creative techniques in order to generate large no of ideas related to material for providing the functional requirement.

- Evaluation phase: It involves analysis of possible developed alternatives. The cost of each idea is estimated.

- Critical evaluation of all points of solution is carried out. The idea with respected to material which promises greatest saving are screened and short listed using short listing techniques like feasibility ranking etc.

- Development phase: It involves investigation of short listed ideas in depth to arrive at optimum and practical solution.

- Presentation phase: The presentation phase involves presentation of selected alternatives to the decision makers for approval and implementation.

- Implementation phase: It involves implementation of results of above phase which is definite, specific and tangible solution tangible solution accepted to all.

To stimulate creative ideas in value engineering a test check list issued which consist of subject, basic questions analysis and answer. As in the subject of material the basic question is asked what is the material specification? and analysis is done by asking following questions like as, can less expensive material be used?, can a more expensive material having easier machining properties?, are the newly developed material that can be used advantageously? and can the size of or weight of material is reduced? After doing this will get answers. The Fig-9 shows the Depiction of value engineering job plan phase and VE Savings Potential during the life of a typical material selection system [19]. By continuously applying VE technique in product can result saving in materials, cost and results increases in functionality, acceptability, sustainability reliability and durability of the SLS fabricated products [18-19]. The cost per part for SLS system is calculated through formula which includes the factor as like, Use full life of machine in years, Depreciation cost per year, Hours per year, Machine cost per hour etc. After finding out the part function and cost per part by various material, design and parameters the value of the part can be analyzed and the part material, parameter and design which imparts greater value with less cost can adopted for fabricating part in SLS process. 


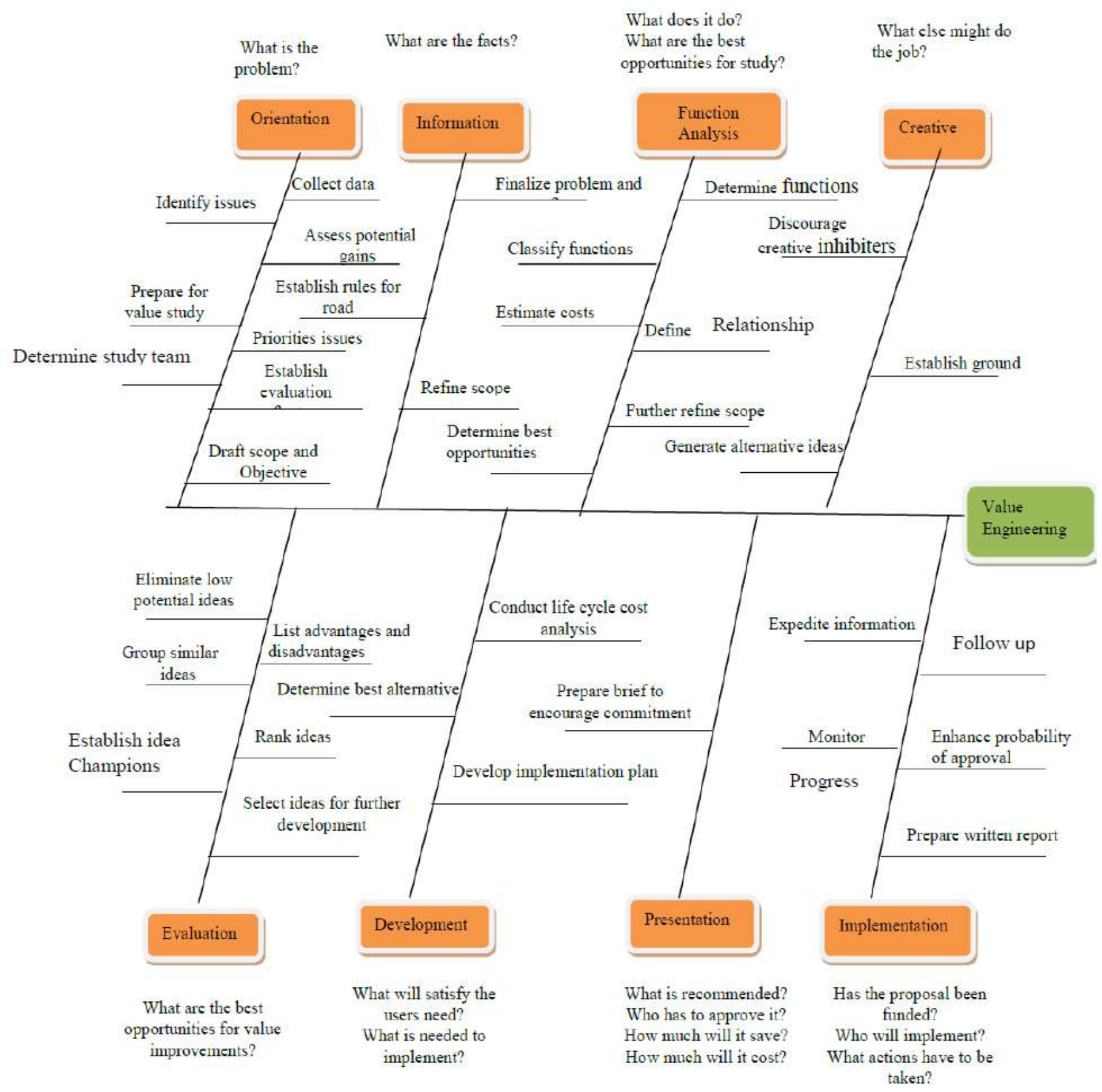

Fig-9: Depiction of value engineering job plan phase [19]

\section{CASE STUDY -MEDICAL COMPONENTS}

The four medical components were taken from Nordson medical [20]. Component 1 is $1 / 16-27$ NPT Thread with 5/16" Hex to 200 Series Barb, 3/16" (4.8 mm) ID Tubing, Nylon (PA2200). Component 2 is Female Luer Lug Style Panel Mount 1/4-28 UNF to 200 Series Barb, 3/32" (2.4 $\mathrm{mm}$ ) ID Tubing, Nylon (PA2200). Component 3 is Female Luer Thread Style to 200 Series Barb, 1/16" (1.6 mm) ID Tubing, Nylon (PA2200) and Component 4 is Blood Pressure 80369-5 compliant Male Bayonet Connector to 500 Series Barb, 1/8" (3.2 mm) ID Tubing, Nylon (PA2200) [20] and are shown in Fig-10, Fig-11, Fig-12, and Fig-13.The $\mathrm{CAD}$ model of these components were prepared according to product given dimension and some of the dimension were taken as per standard. The existing products were analyzed using value engineering technique. The material selection is made and it is found that depending upon strength required by product nylon 12 (PA2200) is more appropriate. Further, optimal process parameter $\left(176^{\circ} \mathrm{C}\right.$ (Part bed temperature), $130^{\circ} \mathrm{C}$ (Removal chamber temperature), 0.12 (layer thickness) etc.) and some other were selected as per standard depending upon PA2200 and SLS machine (EOS INT 
P395). The optimized end used medical component parts were fabricated using above standard. The SLS fabricated parts on shown in Fig-10, Fig-11, Fig-12, and Fig-13. It is found that apply of Value Engineering in medical component development made significant improvement in functionality of the cost as well it has reduces the cost of the product. Finally it is concluded that Value Engineering is proven tool for new product development with a view to optimize design of product, deciding and setting of optimal parameter of getting better part properties, selection of material and to get it in feasible cost range.

Component 1 is 1/16-27 NPT Thread with 5/16" Hex to 200 Series Barb, 3/16" (4.8 mm) ID Tubing, Nylon (PA2200). Component 2 is Female Luer Lug Style Panel Mount 1/4-28 UNF to 200 Series Barb, 3/32" (2.4 mm) ID Tubing, Nylon (PA2200). Component 3 is Female Luer Thread Style to 200 Series Barb, 1/16" (1.6 mm) ID Tubing, Nylon (PA2200) and Component 4 is Blood Pressure 80369-5 compliant Male Bayonet Connector to 500 Series Barb, 1/8" (3.2 mm) ID Tubing, Nylon (PA2200).
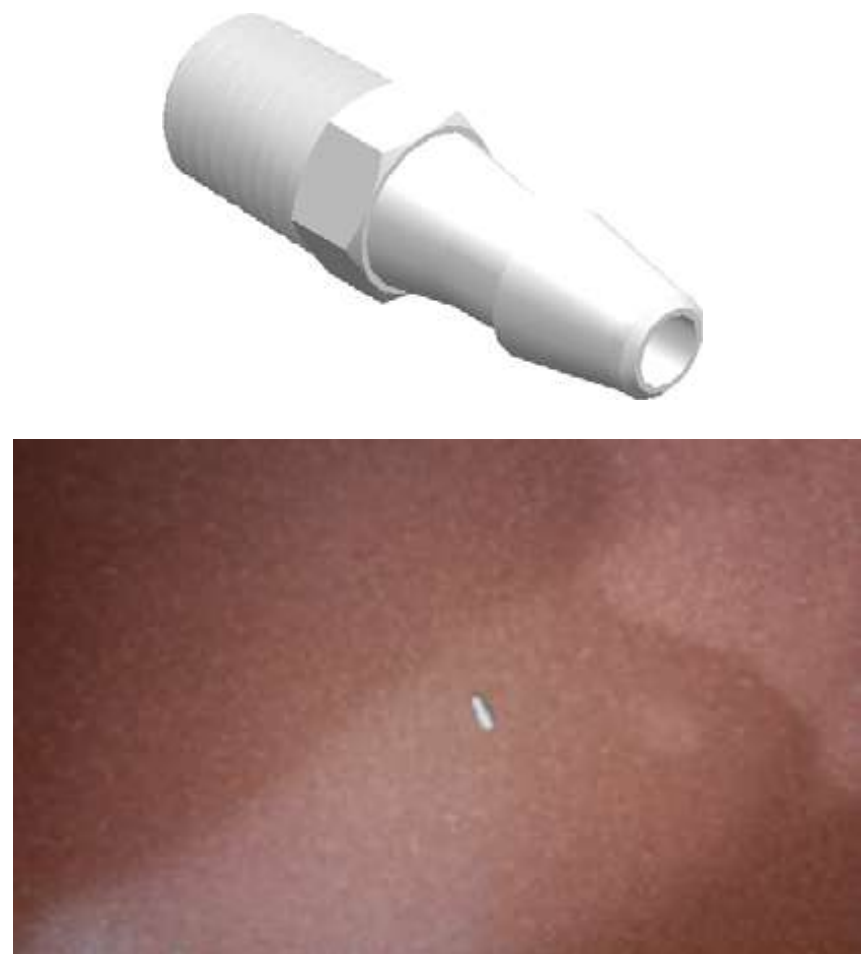

Fig-10: 1/16-27 NPT Thread with 5/16" Hex to 200 Series Barb, 3/16" (4.8 mm) ID Tubing, Nylon (PA2200)

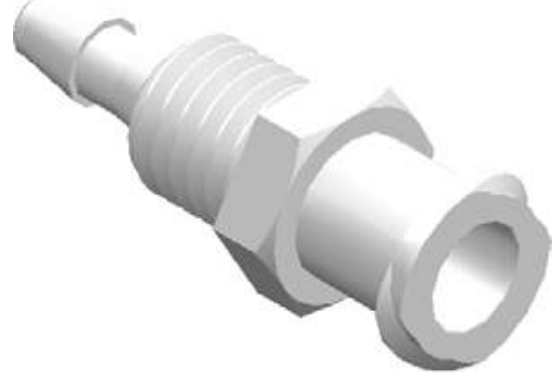

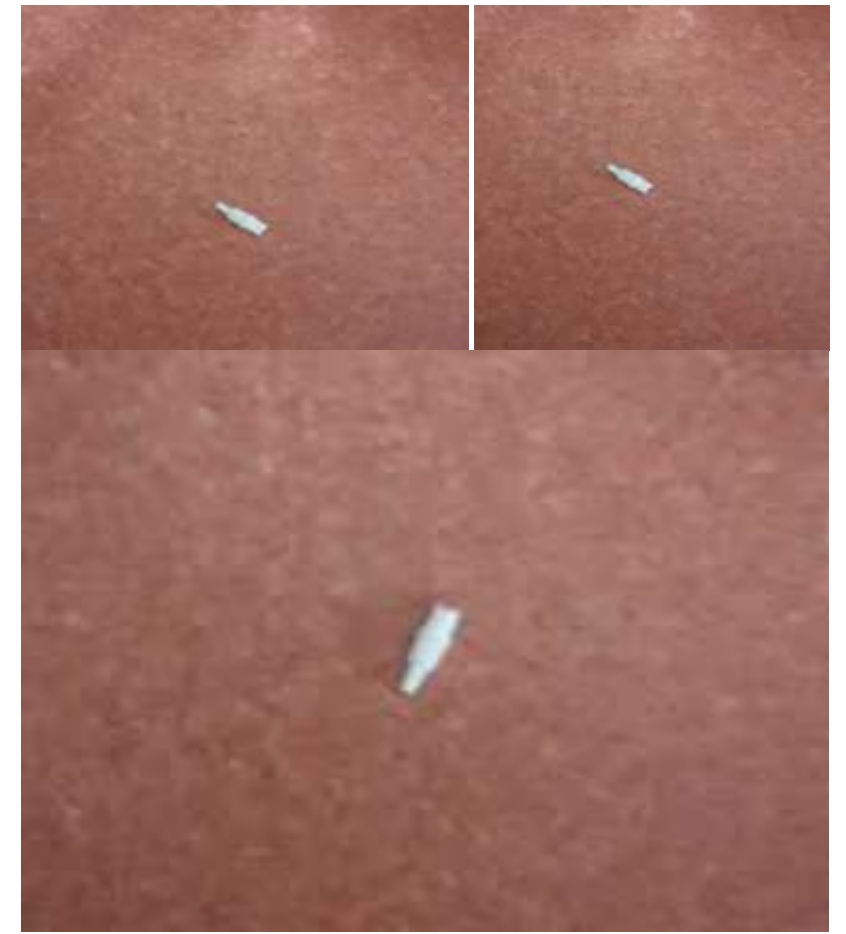

Fig-11: Female Luer Lug Style Panel Mount 1/4-28 UNF to 200 Series Barb, 3/32" (2.4 mm) ID Tubing, Nylon (PA2200).
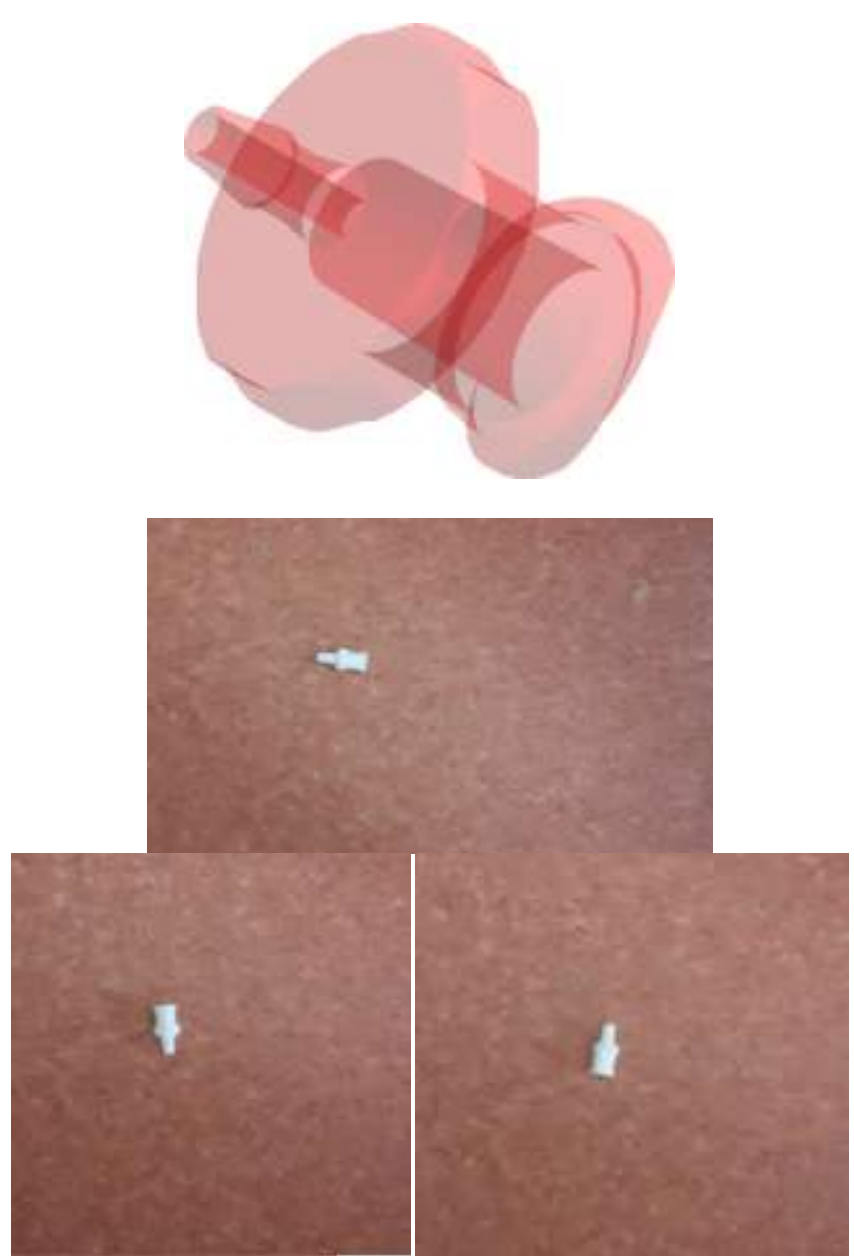

Fig-12: Female Luer Thread Style to 200 Series Barb, 1/16" (1.6 mm) ID Tubing, Nylon (PA2200). 

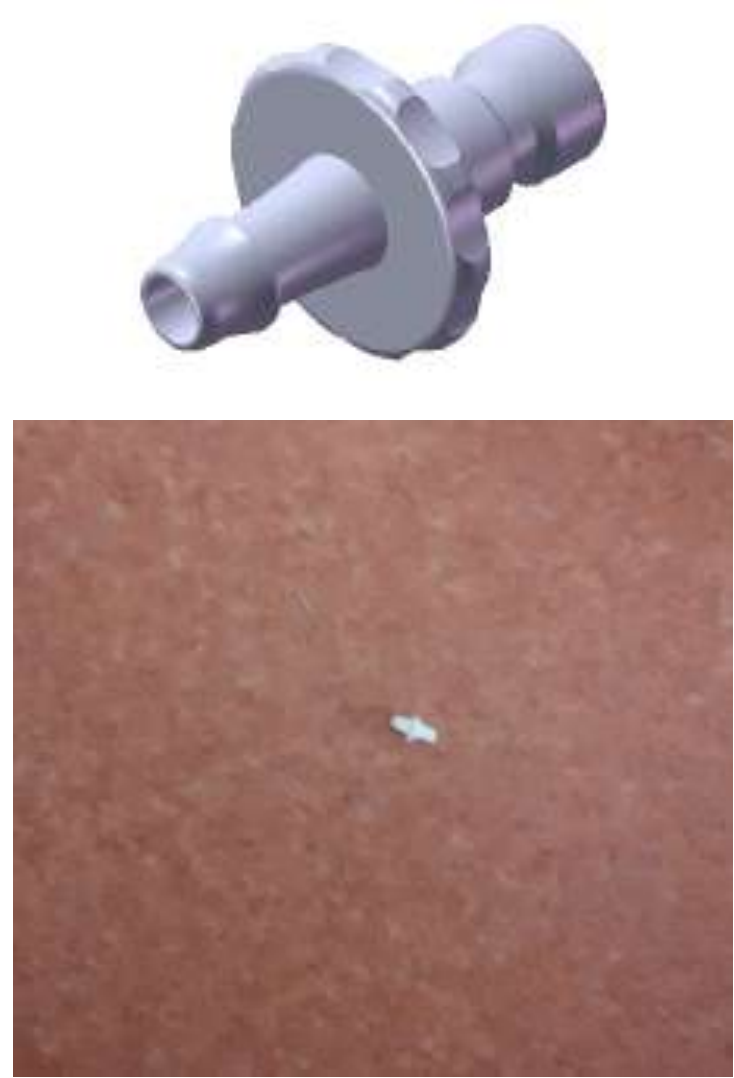

Fig-13: Blood Pressure 80369-5 compliant Male Bayonet Connector to 500 Series Barb, 1/8" (3.2 mm) ID Tubing, Nylon (PA2200).

\section{CONCLUSION}

Additive Manufacturing includes a set of emerging technologies. AM have capability to fabricate high geometrical parts and it becomes a serious competitor to machining and forming technologies. Due to their obvious process control and modelling and new design tool and software will increase acceptability of this technique with advantages in product customization, maximum material savings, energy saving and gradual and controlled porous structures, additive technologies are becoming more interesting to many industrial sectors such as biomedical, aerospace, automotive, tooling, art, architectural, geographic information system (GIS) and Hobby. With the introduction of new materials, high power lasers and active principles, the AM technologies that originally were only used for prototypes and models have now been converted into technologies that can fabricate fully-dense functional parts with high added value. The high cost of material which result high cost of fabricated product and fabricating high dense part as of conventional manufacturing techniques is still a challenge for AM processes. To make it as of conventional manufacturing Value Engineering practices will play vital role to eliminate unnecessary wastes and improving functionality of AM process. The Value Engineering (VE) is used to optimize the material for SLS process as material contributes 70 percentage of total cost of product. The VE principles help in proper selection of SLS material among the available material alternatives satisfying the user requirements for specific application field. The use of VE optimizes the function of the part or subassembly or assembly fabricated by the SLS process with saving in the cost by critically examining every factor and eliminating the thing those are not adding any value to the product. In future, with the continues use of VE in SLS process there is opportunity for fabricating high strength part with and without a tailored property at low cost. Apart from this development of more new materials, material data base containing material properties and information related to the performance of fabricated part of chosen material, fabrication parameter and material properties relationship. In this study fabrication of medical components/devices cases included to show gain improvement in SLS process material using VE approach.

\section{ACKNOWLEDGEMENT}

This paper is revised and extended version of paper title "Material optimization in Selective Laser Sintering Process using Value Engineering approach" presented in national conference "NCRAFT'13", October 2013, OIST, Bhopal, India.

\section{REFERENCES}

[1] S. K. Tiwari, S. Pande, S. Agrawal, S.M. Bobade, Selection for selective laser sintering materials for different applications, Rapid Prototyping Journal, 21(6) pp. 630-648, 2015.

[2] S. K. Tiwari, S. Pande, Material properties and selection for selective laser sintering process, International Journal of manufacturing Technology and Management, 27 ( 4/5/6), pp.198-217, 2013.

[3] P. K. Jain, K. Senthilkumaran, K. Pandey, P. M. Rao and P. V. M., "Advances in material for powder based RP. Proceeding of International Conference on Recent Advances in Materials and Processing," PSG-Tech. Coimbatore, India, 2006.

[4] L .Cucuruz, M. Nicoara, A. Raduta and Locovei C. (2010) "Contributions to optimization of properties for components fabricated by mean of selective laser sintering from composed materials," Selected Topics in Energy, Environment, Sustainable Development and Landscaping [online]. Available: http://www.wseas.us /elibrary/conferences/2010/TimisoaraP/EELA/EELA21.pdf

[5] O. Diegel, S. Singamaneni, S. Reay and A. Withell, "Tool for sustainable product design: additive manufacturing," Journal of Sustainable Development, vol. 3, pp. 68-75, 2010.

[6] D. King, T. Tansey, "Alternative materials for rapid tooling," Journal of Materials Processing Technology, vol. 121, pp. $313-317,2002$.

[7] R. I. Campbel, D.J. D. Beer and E. Pei, "Additive manufacturing in South Africa: building on the foundations," Rapid Prototyping Journal, vol. 17, no. 2, pp. 156-162, 2011.

[8] S. Kalpakjain and S. R. Schmid, Manufacturing engineering and technology. 4th ed., Pearson, 2011.

[9] S. Choudha, S. K. Tiwari and S. Pande, "A review of different selection procedures for additive 
manufacturing process," in Proc. 17th annual conference of Gwalior academy of mathematical science \& information technology, 2012, Guna, India

[10] S. K. Tiwari and S. Pande, "Review of material properties and selection for selective laser sintering process," in Proc. InnDeM-2012, 2012, Jabalpur, India.

[11] T. Wohlers, "Additive manufacturing and 3D printing state of the industry," Annual worldwide progress report, Wohlers Associates, Inc. USA, 2012.

[12] T. Wohlers, "Additive manufacturing and 3D printing state of the industry," Annual worldwide progress report, Wohlers Associates, Inc. USA, 2011.

[13] I. Gibson, W. D. Rosen and B. Stucker, Additive manufacturing technologies: rapid prototyping to direct digital manufacturing, 1st ed., Springer P10ublishers, UK, 2010.

[14] (2012) The Custom Part Net website [online]. Available: http://www.custompartnet.com/.

[15] C. K. Chua, K. F. Leong and Lim, C. S., Rapid prototyping: principles and applications, 2nd ed., World Scientific Publishing Co. Pvt. Ltd, 2010.

[16] K. V. Wong, H. Aldo, (2012). A Review of Additive Manufacturing. Available:www.isrn.com/journals /me/aip/208760.pdf. 2012.

[17] M. Mahajan, "Industrial Engineering \& Production management", Dhanpat Rai Pub. Ltd, India, 2007.

[18] A.K. Mukhopadhyaya, "Value engineering Concepts, Techniques and applications," Sage publications, New Delhi, India.

[19] USA, Defense department. "Value Engineering: A Guidebook of Best Practices and Tools", 2011.

[20] Nordson Medical<http://www.nordsonmedical. com/> (Accessed on $7^{\text {th }}$ December, 2015).

\section{BIOGRAPHIES}

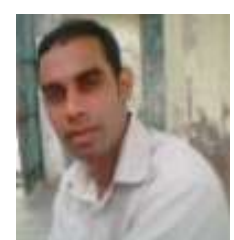

Sunil Kumar Tiwari is Associate Professor in the Department of the Mechanical Engineering at the Lakshmi Narain College of Technology and Science, Bhopal, India. $\mathrm{He}$ is $\mathrm{PhD}$ research scholar in Department of Mechanical Engineering at the Jaypee University of Engineering and Technology, Guna, India. His research interest includes issue related to, material optimization for additive manufacturing and its bio-medical applications, value engineering (VE), optimal use of resources to enhance productivity. Sunil Kumar Tiwari is the corresponding author and can be contacted at: suniltiwari2259@rediffmail.com.

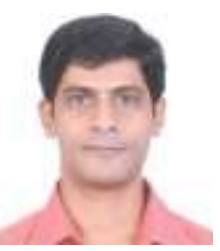

Sarang Pande is a Professor in the Department of the Mechanical Engineering at the Marwadi Education Foundations Group of Institutions, Rajkot, India. His research interest includes issues related to micro-manufacturing, computeraided process planning, machine-tool technology, material optimization for additive manufacturing and its bio-medical applications.

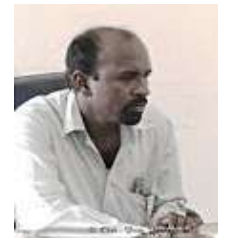

Santosh M. Bobade is an Assistant Professor in the Department of the Physics at the Jaypee University of Engineering and Technology, Guna, India His research interest includes solid state ionics, semiconducting device processing, flash memories, thin film transistors and ferroelectric materials. Prior to joining JUET Guna, from 2007 to 2010, he was working as BK-21 Fellow in Sungkyunkwan University (Suwon), Hanyang University (Seoul) and Sogang University (Seoul) South Korea. 